\title{
Pregnancy in the FONTAN palliation: physiology, management and new insights from bioengineering
}

\author{
Maria Victoria Ordoñez ${ }^{1,2^{*}}$ (D) Giovanni Biglino ${ }^{1,2,3}$, Massimo Caputo ${ }^{1,2}$ and Stephanie L. Curtis ${ }^{1}$
}

\begin{abstract}
Fontan palliation for the single ventricle results in a challenging and delicate physiological state. At rest, the body adapts to a low cardiac output and high systemic venous pressure. However, when physiological demands increase, such as in the case of exercise or pregnancy, this delicate physiology struggles to adapt due to the inability of the heart to pump blood into the lungs and the consequent lack of augmentation of the cardiac output.

Due to the advances in paediatric cardiology, surgery and intensive care, today most patients born with congenital heart disease reach adulthood. Consequently, many women with a Fontan circulation are becoming pregnant and so far data suggest that, although maternal risk is not high, the outcomes are poor for the foetus. Little is known about the reasons for this disparity and how the Fontan circulation adapts to the physiological demands of pregnancy.

Here we review current knowledge about pregnancy in Fontan patients and explore the potential role of computational modelling as a means of better understanding this complex physiology in order to potentially improve outcomes, particularly for the foetus.
\end{abstract}

Keywords: Fontan palliation, Congenital heart disease, Pregnancy, Foetus, Single ventricle

\section{Key principles of pregnancy physiology}

Normal pregnancy is associated with considerable physiological stress. As a dynamic process associated with significant haemodynamic and hormonal changes, it has a huge impact on the cardiovascular system. These changes are adaptive mechanisms to meet the increased metabolic demands of the foetus to ensure adequate uteroplacental circulation for foetal growth and development $[1,2]$. Higher levels of oestrogen and progesterone cause increased vasodilation and reduced systemic vascular resistance. A healthy heart then increases heart rate and stroke volume

\footnotetext{
* Correspondence: Victoria.Ordonez@uhbw.nhs.uk

'Bristol Heart Institute, University Hospitals Bristol \& Weston NHS Foundation Trust, Bristol, UK

${ }^{2}$ Bristol Medical School, University of Bristol, Bristol, UK

Full list of author information is available at the end of the article
}

to increase cardiac output to the fetoplacental unit [3]. Cardiac output and stroke volume double, myocardial oxygen consumption increases by $20 \%$ and heart rate by $15-20 \%[2,3]$. In a normal pregnancy, there is also substantial activation of the renin-angiotensin-aldosterone system, which increases incrementally alongside oestrogen production. Cardiac structural changes occur as a consequence of these hemodynamic changes. The size and volumes of both ventricles increase as well as the thickness of the myocardium, accompanied by a transitory detriment in contractility. All of these changes (Fig. 1) are reversible following a normal pregnancy and are considered part of the body's adaptation to pregnancy [1-3].

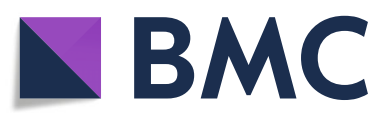

(c) The Author(s). 2021 Open Access This article is licensed under a Creative Commons Attribution 4.0 International License, which permits use, sharing, adaptation, distribution and reproduction in any medium or format, as long as you give appropriate credit to the original author(s) and the source, provide a link to the Creative Commons licence, and indicate if changes were made. The images or other third party material in this article are included in the article's Creative Commons licence, unless indicated otherwise in a credit line to the material. If material is not included in the article's Creative Commons licence and your intended use is not permitted by statutory regulation or exceeds the permitted use, you will need to obtain permission directly from the copyright holder. To view a copy of this licence, visit http://creativecommons.org/licenses/by/4.0/. The Creative Commons Public Domain Dedication waiver (http://creativecommons.org/publicdomain/zero/1.0/) applies to the data made available in this article, unless otherwise stated in a credit line to the data. 


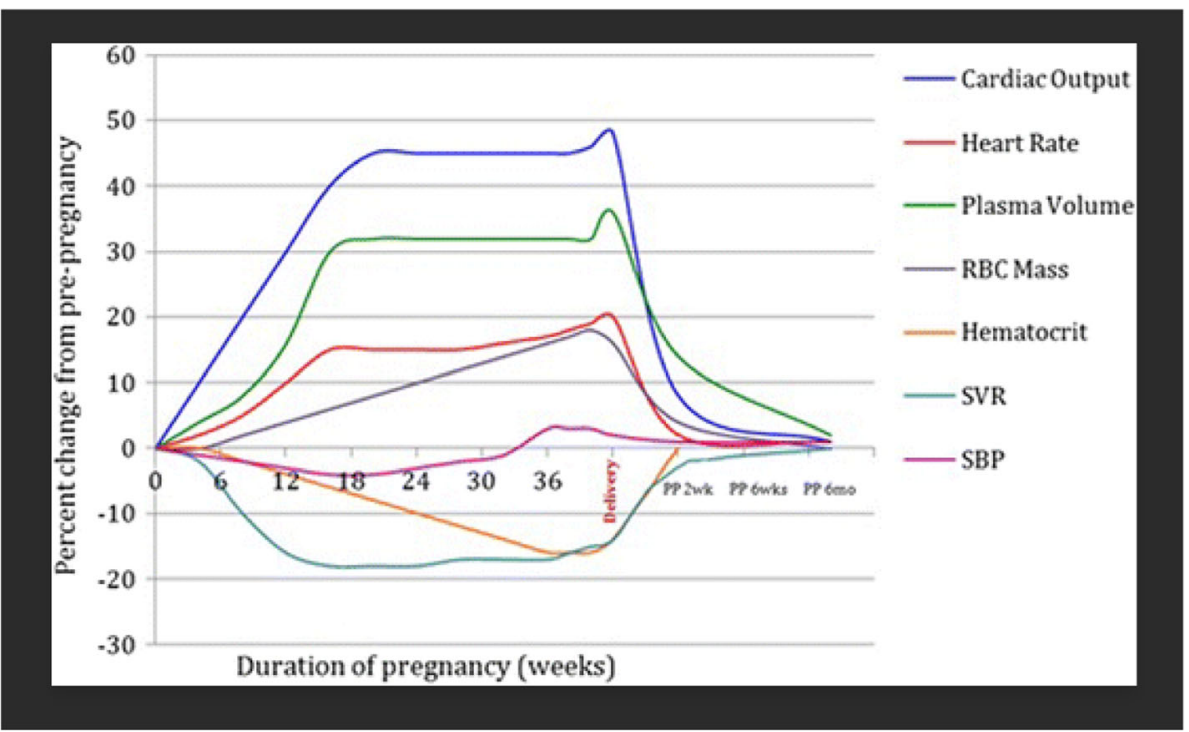

Fig. 1 Hemodynamic changes during pregnancy, delivery and the post-partum period. Reproduced with permission from Dr. DeFaria Yeh Doreen [4]

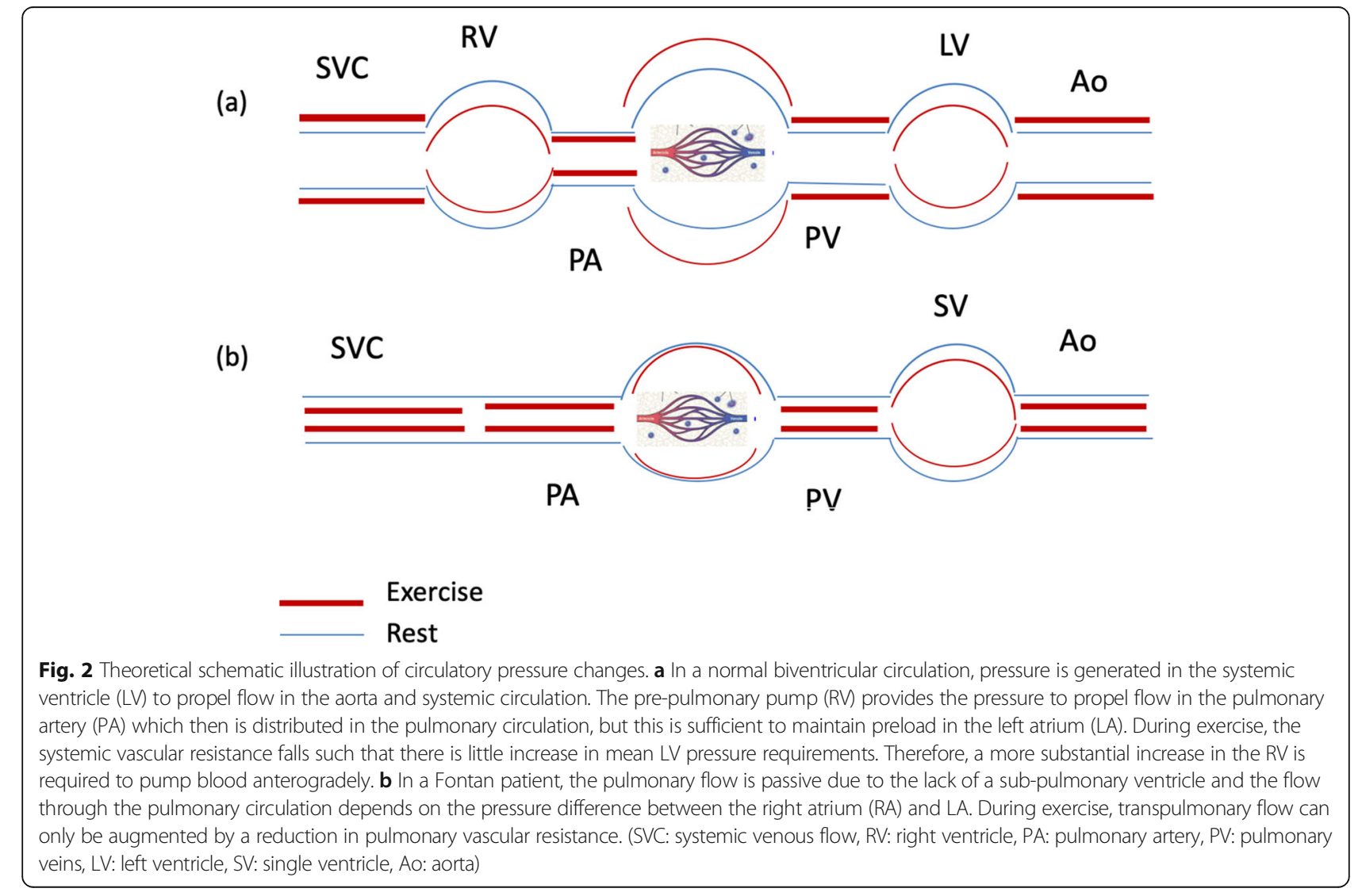




\section{Key principles of the FONTAN physiology}

A univentricular circulation describes a congenital heart defect where a biventricular repair is not possible [5]. The Fontan repair offers offloading of the single ventricle and improvement in oxygenation at the expense of low cardiac output and increased systemic venous pressure. In a Fontan circulation there is no pump to propel the blood into the pulmonary arteries since the systemic veins are directly connected to the pulmonary arteries [5]. The postcapillary energy is used to drive blood through the lungs, though hampered by the pulmonary impedance. Therefore, pulmonary vascular resistance (PVR) is the key factor influencing normal ventricular filling and in turn cardiac output (CO), rather than the contractility of the ventricle itself, as expected in a biventricular physiology [5].

Under exercise conditions, an increase in stroke volume and pulmonary artery pressure is observed in a biventricular circulation. A pre-pulmonary pump is required to generate the pressure and flow, which enables adequate left ventricular (LV) filling during exercise. However, in the absence of a pre-pulmonary pump and without adequate preload, $\mathrm{CO}$ cannot increase during exercise [6]. Furthermore, chronotropic incompetence may occur due to scar-related sinus node dysfunction and due to abnormal reflex control of heart rate or adrenergic dysfunction [7]. The lack of increase in CO can be partially explained by a number of factors, such as: chronotropic incompetence, impaired pulmonary function (as a consequence of thoracotomy), high pulmonary vascular resistance and inadequate augmentation of preload during exercise (Fig. 2). Therefore, patients with a Fontan circulation poorly tolerate preload changes due to their inability to increase $\mathrm{CO}$ against higher demands. Based on the same principle, pregnancy-related haemodynamic changes represent a considerable, additional burden for a univentricular heart [8].

\section{The combination of two complex physiologies: pregnancy in FONTAN patients}

Pregnancy is a challenge for the normal heart, based on the hemodynamic and structural changes described above, but a bigger challenge for the Fontan circulation. Understanding the interactions between pregnancy and Fontan hemodynamics, as well as being aware of the potential obstetric complications that may arise, is fundamental to provide counselling and sound medical care to women with a Fontan circulation undergoing pregnancy.

From a physiological standpoint, it must be borne in mind that the haemodynamic changes in pregnancy are not insignificant for Fontan patients. The low cardiac output resulting from single ventricle palliation is relatively well tolerated at rest but poorly when the demand increases in pregnancy. Increasing the $\mathrm{CO}$ by $50 \%$ is simply not possible for the Fontan circulation. Furthermore, diastolic function is inherently abnormal in the Fontan $[2,3,5,6]$ and therefore the increase in heart rate that is associated with pregnancy further compromises the efficiency of the circulation.

The Fontan circulation is unique in that, in the absence of a sub-pulmonary ventricle, it relies on chronically elevated venous pressure in order to drive blood through the pulmonary vessels [9]. Elevated intrahepatic pressure is a long-term complication, which can lead to cirrhosis and portal hypertension. The additional effect of the foetus resting on the IVC and the increasing plasma volume results in further increasing portal venous pressure and this 'venous stagnation' may add to the adverse uterine environment for the foetus. This has not been studied but a similar situation exists in cirrhosis due to other causes. Pregnancy in women with cirrhosis is uncommon as fertility is reduced but the existing evidence points to poor foetal outcomes with increased rate of miscarriage, preterm labour and perinatal death [10].

\section{Outcomes during pregnancy in a UNIVENTRICULAR physiology}

Thanks to some landmark papers in the field of obstetric cardiology $[5,11,12]$, we know that cardiac risk in pregnancy is increased by a number of key factors, namely reduced ventricular function, increased New York Heart Association (NYHA) functional class, cyanosis, the presence of a mechanical valve, reduced right ventricular function in the context of severe pulmonary regurgitation, significant left sided valve obstruction and risk of aortic dissection in women with connective tissue disorders. Several scores exist in order to translate these factors into a prediction of risk of adverse events in pregnancy for an individual woman. Similarly we know that foetal outcomes are also adversely affected by reduced ventricular function, increased NYHA functional class and cyanosis, but also by smoking and drugs such as warfarin.

However, the prevalence of univentricular hearts in the population is low and therefore Fontan pregnancies were not well represented in these studies. More recent data has suggested that, though traditional risk scores can help to predict events in the mother, foetal outcomes are significantly worse than expected [13].

The recent European Society of Cardiology (ESC) guidelines on heart disease in pregnancy put the 'good Fontan' in modified World Health Organisation (mWHO) III for risk, equating to a "significantly increased risk of maternal mortality or severe morbidity". For a Fontan "with any complication" the risk is mWHO IV: an extremely high risk of maternal mortality or severe morbidity. This advice comes from the little but increasing body of evidence available on this specific group of patients [14]. 
Theoretically we might expect therefore that the increased volume load of pregnancy will increase the risk of heart failure in the Fontan and that the enhanced adrenergic receptor excitability mediated by oestrogens and progesterone may trigger the development of arrhythmias. We might also expect that anticoagulation may cause problems for mother and foetus. It is logical that the foetus will be adversely affected by the reduced cardiac output and therefore foetal loss will be increased. All of these assumptions are borne out by the existing literature but it is perhaps surprising just how poor foetal outcomes are, even in a 'good' Fontan. Maternal outcomes are actually quite good. The ESC guidelines are correct in indicating the high risk to the foetus but the proposed high risk of maternal mortality or severe morbidity is not borne out by the literature.

\section{Maternal complications}

The existing literature suggests that indeed the most common risks to the mother in the Fontan pregnancy are of arrhythmias, heart failure and thromboembolic or bleeding events [15-17]. Overall, however, these risks are relatively low and patients have been reported as having been managed effectively and without long-term sequelae $[18,19]$. Maternal death has not been reported (Table 1).

\section{Arrhythmia}

The most common maternal cardiac complication reported during pregnancy is supraventricular arrhythmia,

Table 1 Maternal, Obstetric and Foetal complications Reported in Fontan Pregnancies

\begin{tabular}{lll}
\hline Maternal complications & Overall prevalence (\%) & Range (\%) \\
\hline Arrhythmias & & \\
SVT & $8.4 \%$ & $3-37 \%$ \\
Heart failure & $3.9 \%$ & $3-11 \%$ \\
Thromboembolism & & \\
Obstetric complications & & $23 \%$ \\
Ante-partum & $11 \%$ & \\
Post-partum & $43 \%$ & \\
Major haemorrhage & $14 \%$ & $27-69 \%$ \\
Foetal complications & & $70-80 \%$ \\
Miscarriages & & \\
Prematurity & & \\
SGA & $60 \%$ & $10-20 \%$ \\
IUGR & $70 \%$ & \\
NND & $5 \%$ & \\
PROM & & \\
\hline
\end{tabular}

SVT Supraventricular tachycardia, SGA Small for gestational age, > haemorrhage (> $2 \mathrm{I}$ ), IUGR Intra uterine growth restriction, NND Neonatal death, PROM Premature rupture of membranes. See text for details described in 15 out of 198 pregnancies with available data (overall prevalence of $8.4 \%$; range 3-37\%) [15]. Arrhythmia occurred mostly in the third trimester and responded to conventional treatment approaches, often cardioversion. In the largest single cohort in the literature, reporting data from the UK, 19 of the women included had a history of arrhythmia but only six of them were affected during pregnancy [18]. No ventricular arrhythmias have been reported but a few cases of bradyarrhythmia requiring pacing have been described [19].

\section{Heart failure}

Heart failure occurs in a significant minority of pregnancies in women with a Fontan circulation. A metaanalysis of the literature reported an overall prevalence of $3.9 \%$ (range $3-11 \%$ ) with one case associated with persistent atrial fibrillation [15]. Women were largely asymptomatic prior to pregnancy [15].

Heart failure occurred, not only in the third trimester, but in the postpartum period in four of the seven cases reported [15]. This is not unexpected, as the haemodynamic changes in the post-partum period are profound. The uterus contracts and auto-transfuses $250 \mathrm{ml}$ of blood into an already volume loaded circulation at a time when myocardial strain is reduced. Also the mass of the foetus is removed from the inferior vena cava, further increasing venous return. Diastolic dysfunction in Fontan patients may also contribute to their increased risk of heart failure in this scenario, as the Fontan heart struggles with the increased volume load.

It is likely that women with a Fontan circulation becoming pregnant have good function of the Fontan circuit and good contractility of the ventricle, which perhaps explains why prompt recovery of function after treatment is common and intractable ventricular failure is not described.

\section{Thromboembolism}

Pregnancy is a pro-thrombotic state. It has been known for many years that the Fontan operation and all its modifications also increases the risk of thromboembolism [15-17]. The reasons for this are complex. Patients are known to have reduced levels of clotting factors Proteins $C$ and S, as well as Factor VII $[20,21]$ and there is recent evidence to suggest that increased liver stiffness may further increase the clotting risk [19].

Therefore, thromboembolic events could theoretically be expected to increase in pregnant Fontan patients and events have been reported in these pregnancies but the numbers are small and it is difficult to draw any conclusions from the existing published data [19].

What is important though is that these patients are generally anticoagulated for the reasons above and to facilitate forward flow. We know that bleeding complications in 
Fontan pregnancies are high, as described below, and thought needs to be given to the balance of bleeding and clotting in Fontan pregnancies. Whether to use antiplatelet agents or low molecular weight heparins, and at what dose, are all unanswered questions.

\section{Obstetric complications}

The most common obstetric complication in women with a Fontan circulation is bleeding. Where it has been documented, most women are either fully anticoagulated or treated with antiplatelet agents [15]. Haemorrhage has been reported in women who were not given any anticoagulant or antiplatelet but the numbers are small and bleeding in pregnancy is common and so it is difficult to draw conclusions from this. It seems logical though that the high risk of bleeding is largely due to the anticoagulation.

Both antepartum and postpartum haemorrhage are common. Antepartum haemorrhage is a consistent finding in a few patients per published study, reported as approximately $11 \%$ overall [15] but it has been reported in as many as $23 \%$ patients [22]. Post-partum haemorrhage, however, is a bigger problem and a recent large UK study found that it occurred in $43 \%$ of deliveries and more importantly, major haemorrhage (>two litres) occurred in seven women (14\%) [21] (Table 1).

\section{FOETAL complications}

Foetal outcomes are extremely poor in the Fontan and this has been described by multiple authors in different countries. The live birth rate has been consistently reported as $40-50 \%[18,19,22]$ or even less [23].

Both first and second trimester miscarriage is common, reported in $27-69 \%$ of cases $[13,19,22-24]$ and in those foetuses that survive, neonatal death is not uncommon, occurring in up to $5 \%$ live births [15]. This is likely to be due to prematurity in many cases, which affects up to $70-80 \%$ live births $[11,13,19,22]$.

Initial reports suggested that prematurity was not necessarily to be expected, with a reported mean gestational age in one study of 36.5 weeks [10]. However, since then, the evidence points to prematurity being the rule with median gestational age in a recent metaanalysis being 32 weeks [15, 25-27]. Premature rupture of membranes occurs in at least $10 \%$ cases $[11,13,19]$, some have reported up to $20 \%$ [28]. Additionally, the rate of preterm labour is higher than in a normal pregnancy.

Poor foetal growth is common and the occurrence of small for gestation age (SGA) babies is the norm. Evidence reported SGA in up to $60 \%$ live births with the median birthweight being on the 9th centile $[22,28]$. Furthermore, rates of intra-uterine growth retardation (IUGR) of $70 \%$ have been reported [22].
It is likely that these early pregnancy losses, as well as the high incidence of prematurity and intrauterine growth restriction, are driven by a combination of factors, including placental insufficiency, adverse hemodynamics including limited cardiac output, neurohormonal environment of the Fontan circulation, maternal medication (e.g. $\beta$ blockers), and iatrogenic prematurity. We know that maternal cyanosis is a risk factor for miscarriage. Although foetal haemoglobin is extremely efficient at extracting oxygen, once saturations are less than $85 \%$ the chances of a live birth are as low as $12 \%[28,29]$. This has been specifically reported in the Fontan population. A recent large multi-centre UK study with the largest pregnancy Fontan cohort in the literature of 124 pregnancies described miscarriage in all eight women in their cohort with oxygen saturations less than $85 \%$, compared to 60 out of 116 (51.7\%) who had baseline saturations of $\geq 85 \%$ [28].

However, most women with a Fontan circulation are not cyanosed and clearly, some women do well. The reasons for this are poorly understood. We can assume, as with cirrhosis, that an adverse uterine environment exists, but we do not know which factors in particular are most harmful to the foetus. Therefore it is extremely difficult to counsel women with a Fontan circulation, aside from describing the known high foetal risks, and no reliable way to avert a poor foetal outcome when it presents in utero.

The placenta is a poorly studied area in this patient group. We recently described a case of a poor outcome in pregnancy in a 'good' Fontan patient, where the placenta was highly abnormal [30]. A small case series [31] has described a variety of placental abnormalities in this patient group, which needs further study and may provide further insights.

It must be borne in mind that, in the case of foetal demise, both surgical removal of the products of conception and delivery of a non-viable foetus are not without risk. Similarly, patients who become pregnant unintentionally and opt for therapeutic termination (7-9\% reported cases) [15] will require a surgical procedure, again not without risk (Table 1).

\section{Clinical management of the pregnant FONTAN Pre pregnancy and estimating risk in the individual patient}

Pregnancy carries varying risks in women with congenital hearts defects even after successful repair. Preconception evaluation is essential for genetic consultation, identifying potential medical and surgical issues before pregnancy in order to improve outcomes [24].

In the case of the Fontan circulation, women are aware from an early age that they have a significant heart problem but have not always had detailed pre-conception counselling. Contraception and pregnancy discussions 
should be initiated prior to conception and ideally during teenage years. Though there is some evidence that menarche is delayed in Fontan patients [32, 33], it is important that these discussion are had early, as part of transition, and prior to transferring care from paediatric to adult services.

Such stratification is based on two elements: (a) maternal risk and (b) foetal risk [12]. Current risks calculators such as CARPREG, ZAHARA and the modified WHO criteria either do not include women with a Fontan circulation, or simply classify them as "high risk". The CARPREG classification includes women with both acquired and congenital heart disease and assigns a point for each predictor (i.e. prior cardiac event, NYHA functional class $>$ II or cyanosis, left heart obstruction, left ventricular ejection fraction $<40 \%$ ). A score of 1 confers $27 \%$ risk of maternal cardiovascular complications and a score $>1$ confers a $75 \%$ risk [15]. The ZAHARA study also identified predictors of adverse maternal events in patients with congenital heart disease [11]. The modified WHO criteria include specific cardiac lesions in addition to clinical cardiac status. It applies to women with acquired as well as congenital heart disease and the risk categories range from low risk (group I) to very high risk (group IV) $[28,29]$.

A thorough assessment of the Fontan should to be done by echocardiography, cardiac magnetic resonance imaging (CMR) and cardiac catheterisation, as well as a biochemical and ultrasound assessment of the liver. Objective exercise data is also useful [25, 34]. If there are any complications, such as cyanosis (oxygen saturations below 90\%), reduced ventricular function, atrioventricular valve regurgitation, arrhythmia history, raised Fontan pressure, protein-losing enteropathy, or thromboembolism, pregnancy should be avoided.

If pregnancy is deemed feasible (albeit high risk), each patient must be individually counselled as to the potential maternal and foetal risks for her, alongside sensitive counselling around parenting beyond infancy in the context of a severe life-limiting heart condition. One encouraging point is that, at this stage, there is no evidence that pregnancy results in deterioration of the clinical status of the Fontan up to 24 months post-partum [18, 19] and that maternal death has not been reported.

One tool that has been recently explored in the context of clinical consultations of CHD patients and parents of children with CHD is the use of patient-specific 3D printed models, to better elucidate aspects of the anatomy [27, 35, 36]. This could be particularly useful for Fontan patients in light of their unique vascular arrangement post Fontan repair, but it has not been systematically evaluated with pregnant Fontan patients. The feasibility of introducing these tools to this group of patients depends on the availability of suitable cross- sectional imaging (i.e. three-dimensional datasets from either cardiovascular magnetic resonance imaging or computed tomography) providing the necessary input data for model making.

Occasionally, intervention pre-pregnancy can be performed in an attempt to improve foetal outcomes, such as collateral occlusion in the case of cyanosis. Medication needs to be reviewed as to whether or not it is safe for the foetus. Patient can be advised that anticoagulation can be continued but that it will be injectable in the form of low molecular weight heparin, rather than oral coumadins. Aspirin can be continued.

Arif et al. have proposed a new risk stratification model for pregnant women with a Fontan circulation [24] (Table 2). It includes predictors of poor clinical outcomes in the Fontan and data from the modified WHO criteria, which is considered to be the best available pregnancy risk calculator in women with congenital heart disease [23, 24, 27, 35] (Table 1). Though this model was created with 55 pregnancies in 21 women, only 13 foetuses were live born. There were more live births in the 'lower risk' group compared to the 'very high risk' group but this did not reach statistical significance (OR 7.60, 95\% CI 1.81-31.97, $p=0.06$ ), potentially due to the low number of live births. As the only method currently available to risk stratify these women, this model certainly warrants further validation [24].

\section{Management and risk reduction during pregnancy}

Multidisciplinary team management with good communication is the key to reducing complications in women with heart disease [27]. The team should involve maternal-foetal medicine specialists, cardiologists with expertise in congenital heart disease and pregnancy, obstetric anaesthetists, haematologists, and specialist midwives. Women should be managed as outpatients in a joint clinic with all specialists and required investigations being available in a one-stop setting.

Women need to be seen on a two to four weekly basis throughout pregnancy, increasing to weekly as the pregnancy progresses. A clinical assessment, electrocardiogram and echocardiogram need to be done at each visit, as well as careful foetal surveillance. A full blood count, liver function tests, urea and electrolytes, and brain natriuretic peptide (BNP) need to be done at least once per trimester.

Medication needs to be reviewed at booking. The role of anticoagulation during a Fontan pregnancy remains unclear. Though anticoagulation is definitely indicated in the presence of atrial thrombus, atrial arrhythmia or history of thromboembolic events [27], the evidence for its benefit in an otherwise uncomplicated Fontan, as mentioned above, is limited. 
Table 2 Proposed risk stratification model for pregnant women with Fontan circulation. Women were classified into lower, intermediate and very high risk. Women were allocated to "intermediate" or "very high risk" groups based on achieving $>=1$ criteria for that group. Adapted from [19]

\begin{tabular}{llll}
\hline & Lower risk & Intermediate risk & Very high risk \\
\hline NYHA class & l & II & IIIIV \\
$\mathrm{SaO} 2 \%$ & $\geq 94 \%$ & $90-93 \%$ & $<90 \%$ \\
$\mathrm{mVO}_{2}(\mathrm{~m} / \mathrm{kg} / \mathrm{min})$ & $>60 \%$ & $50-60 \%$ & $<50 \%$ \\
$\mathrm{Systemic} \mathrm{ventricular} \mathrm{function} \mathrm{impairment}$ & none & mild & Moderate/severe \\
AWR & none/mild & moderate & Severe \\
Fontan related complications & none & none & At least one \\
Failing Fontan & no & no & Yes \\
\hline
\end{tabular}

AVVR Atrioventricular valve regurgitation, mVO2 Maximal oxygen uptake, NYHA New York Heart Association, SaO2 Oxygen saturations

There is however a real risk of bleeding, as described above, and anticoagulation has been associated with an adverse neonatal outcome [19] (OR $=10.0,95 \%$ CI [1.591.4], $p<0.01$ ), as well as the risk to the mother from haemorrhage. Some authors have recommended prophylactic anticoagulation by low-molecular-weight heparin (LMWH) in patients with low thromboembolic risk, and therapeutic anticoagulation by LMWH in women with high thromboembolic risk (i.e. past history of arrhythmia or thromboembolic event) but with no real evidence to back up this recommendation [6].

If complications occur, these should broadly be treated as for any woman who is not pregnant, with a few caveats. For example, supraventricular arrhythmias should be treated in the usual way in the Fontan, with a low threshold for cardioversion in cases of sustained arrhythmia. Patients need to be kept hydrated if cardioversion is delayed. $\beta$-blockers can be used for arrhythmia prevention, although they result in an increased risk of IUGR in an already compromised foetus [28]. Full anticoagulation is recommended if not already in place.

Heart failure management in complex congenital heart disease should be individualised [6]. Angiotensinconverting-enzyme (ACE) inhibitors and angiotensin receptor blockers are contraindicated in pregnancy but $\beta$ blockers, alpha-blockers and nitrates can be used as well as loop diuretics. Deterioration of ventricular function however usually prompts delivery of the foetus for the sake of the mother's health and post-partum any drugs can be used, though care should be taken with regard to their excretion into breast milk. As always in obstetric cardiology, if the mother's life is at risk, the best available treatment should be instigated with secondary consideration being given to the foetus.

Delivery should be planned early, given the high risk of foetal demise, but clearly extreme prematurity should be avoided if possible. Vaginal delivery is the aim with a carefully titrated epidural and assisted second stage but, due to the need for premature delivery, Caesarean section has been required in $60-80 \%$ cases $[19,22,28]$. A senior team needs to be involved from an anaesthetic and obstetric point of view. There should be a low threshold for invasive monitoring.

Large boluses of intravenous fluid should be avoided but patients need to be kept well hydrated to maintain left atrial pressure. Ergometrine should be avoided in the third stage and any haemorrhage treated promptly but carefully.

\section{Management post-partum}

The post-partum period is associated with an additional haemodynamic challenge as the uterine blood is autotransfused back into the circulation and the direct pressure on the inferior vena cava from the mass of the baby is relieved. This $48-72 \mathrm{~h}$ period after delivery is a time of increased risk in women with heart disease and often when cardiac events occur, particularly in those at risk of ventricular decompensation.

Fontan patients should remain in an intensive care environment for at least $24-48 \mathrm{~h}$ after delivery. Careful fluid balance, heart rate and blood pressure monitoring are essential during this time $[26,27]$.

A comprehensive echocardiographic assessment should be performed before discharging the patient from hospital, looking at the Fontan conduit flow, presence of thrombus, atrioventricular valve and single ventricle function. Thromboembolic prophylaxis should be continued at least for 6 weeks after pregnancy. Therapeutic anticoagulation should be restored, based on centre policy, once any post-partum bleeding has settled. Continuing low molecular weight heparin for several weeks is a good way of avoiding severe haemorrhage after delivery, which can be unpredictable and difficult to manage on oral anticoagulation therapy.

\section{New insights}

In addition to recent advances in medical imaging, such as 4D MRI that is proving to be particularly insightful in Fontan patients [35-37], one tool that could potentially shed light into the mechanisms of hemodynamic 
adaptation to pregnancy in a complex circulation such as the Fontan is computational modelling. Computational models, in the form of computational fluid dynamics (CFD) or multiscale/multiphysics simulations have been used for many years in the context of evaluating the Fontan circulation. Indeed, probably because of the complexity of the Fontan anatomy and its unique fluid dynamics, modellers have been studying flow distribution in the total cavopulmonary connection (TCPC) since the 1990s [35].

Computational modelling has been used to evaluate different aspects of the Fontan circulation at all stages of palliation, including flow distribution in different TCPC configurations, the hybrid Norwood circulation [38], changes in coronary perfusion [38] and virtual surgery to address pulmonary arteriovenous malformations in Fontan patients [39]. It has also been used for exploring innovations for the surgery itself including the $\mathrm{Y}$ graft baffle for Fontan completion, the assisted bi-directional Glenn and a physiological Fontan connection [39-42].

Computational models, including lumped-parameter models, of the Fontan physiology can also be used to simulate exercise and test the physiological impact of the typical dysfunction that occurs in these patients [43, 44]. Finally, computational models have also been used to explore pregnancy physiology $[45,46]$, including studying utero-ovarian blood flow and uterine hemodynamics, including pulsatility indices (Fig. 3).

Whilst, to our knowledge, a full computational model of the Fontan circulation during pregnancy has not yet been described, computational methodologies certainly hold potential for performing parametric studies and predictive simulations, ultimately generating new insights into this complex physiological scenario. This also extends to modelling the imaging data that can be gathered clinically, as in the case of a study that performed principal component analysis based on flow curves derived from the MRI scans of paediatric patients who underwent single ventricle palliation culminating in a Fontan procedure, describing a relationship between the diastolic flow variations in the pulmonary arteries and the single ventricle function and volumes [47]. Reducedorder modelling can also play a role in this context, as in the case of a biomechanical closed-loop model of the heart coupled with a simplified circulation allowing to perform patient-specific simulations and studying parameters such as myocardial stiffness, contractility at rest, contractile reserve during stress and changes in vascular resistance, providing insights into the pathophysiological response to stress in Fontan patients [48]. As in the above-mentioned case (Kung et al.), such simulations of exercise response can be important also in the context of pregnancy physiology, in light of the fact that pregnancy can be considered as a "stress test" to a woman's cardiovascular system [49].

Refining computational modelling of both the Fontan circulation and pregnancy can hold promise to increase the understanding of a complex physiology adapting under stress, including the uterine environment and factors mentioned earlier e.g. variations in portal pressures and IVC compression.

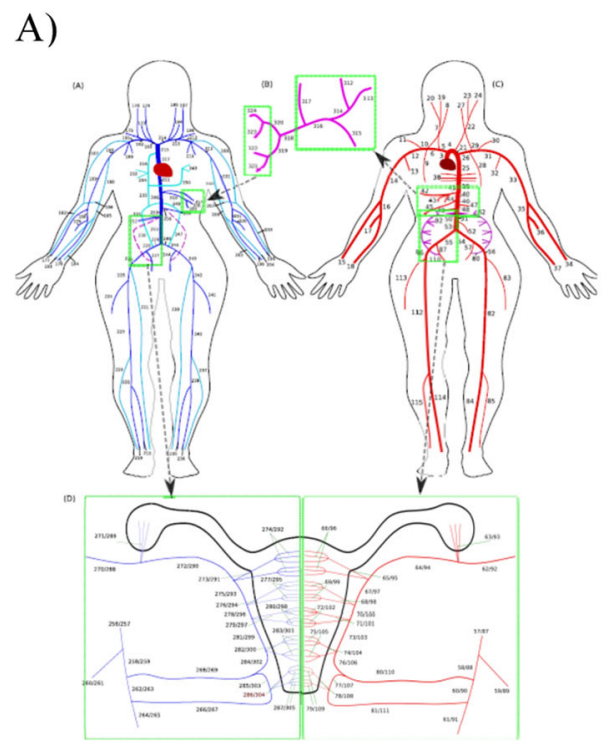

B)

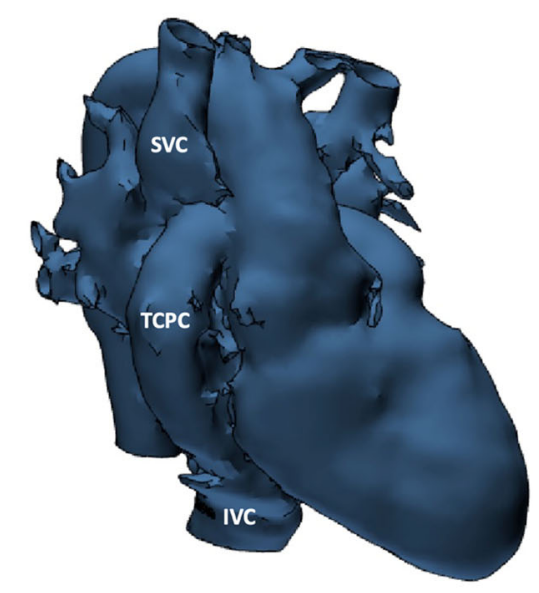

Fig. 3 a Pregnancy physiology simulation scheme, based on a closed-loop 1D-0D modelling framework, as discussed in [45, 46]; b 3D model of full heart and vessels in a Fontan patient clearly showing the single ventricle and the total cavopulmonary connection (TCPC, extracardiac Fontan); the same file can be 3D printed, allowing for the 1:1 replica to be used in the clinical context for counselling purposes 


\section{Conclusion}

There are a number of unanswered questions with regards to pregnancy in the Fontan. We still don't know quite why the foetus has such a poor outcome, both in terms of foetal loss and poor growth and also why some foetuses have a much better outcome than others. We do not fully understand the complex relationship between the foeto-placental unit, the Fontan and the liver and what maternal factors are most important (for example type of Fontan, function of ventricle and so on). We do not know the role of anticoagulation but given the high risk of haemorrhage, both antepartum and postpartum, consideration needs to be given to whether or not this ought to be given during pregnancy and at what dose. We need to know how to best counsel an individual woman about her risk, and how it might be reduced.

Further study of the placenta in Fontan patients and collaborations between cardiologists and bioengineers in designing a computational model of the pregnant Fontan, may help to answer some of these questions.

\section{Acknowledgments}

The authors thank Drs Raoul Van Loon and Jason Carson of Swansea University for providing the pregnancy model illustration. The authors also acknowledge the generous support of the Grand Appeal (Bristol Royal Hospital for Children Charity) and the British Heart Foundation.

\section{Authors' contributions}

All authors were enrolled in the writing process. The authors read and approved the final manuscript.

\section{Funding}

None.

\section{Availability of data and materials}

Not applicable.

\section{Declarations}

Ethics approval and consent to participate

Not applicable.

\section{Consent for publication}

Not applicable.

\section{Competing interests}

Nothing to declare.

\section{Author details}

${ }^{1}$ Bristol Heart Institute, University Hospitals Bristol \& Weston NHS Foundation Trust, Bristol, UK. ${ }^{2}$ Bristol Medical School, University of Bristol, Bristol, UK.

${ }^{3}$ National Heart and Lung Institute, Imperial College London, London, UK.

Received: 28 May 2020 Accepted: 21 February 2021

Published online: 03 May 2021

\section{References}

1. Lui GK, Saidi A, Bhatt AB, Burchill LJ, Deen JF, Earing MG, Gewitz M, Ginns J, Kay JD, Kim YY, Kovacs AH. Diagnosis and management of noncardiac complications in adults with congenital heart disease: a scientific statement from the American Heart Association. Circulation. 2017;136(20):e348-92.

2. Sanghavi M, Rutherford JD. Cardiovascular physiology of pregnancy. Circulation. 2014;130(12):1003-8.
3. Hunter S, Robson SC. Adaptation of the maternal heart in pregnancy. Br Heart J. 1992:68(6):540.

4. Lau E, Yeh DD. Management of high risk cardiac conditions in pregnancy: anticoagulation, severe stenotic valvular disease and cardiomyopathy. Trends Cardiovasc Med. 2019;29(3):155-61.

5. Clift $P$, Celermajer D. Managing adult Fontan patients: where do we stand? Eur Respir Rev. 2016;25(142):438-50.

6. Gewillig M, Brown SC. The Fontan circulation after 45 years: update in physiology. Heart. 2016;102(14):1081-6.

7. Ohuchi H. Cardiopulmonary response to exercise in patients with the Fontan circulation. Cardiol Young. 2005;15(S3):39.

8. Jain VD, Moghbeli N, Webb G, Srinivas SK, Elovitz MA, Paré E. Pregnancy in women with congenital heart disease: the impact of a systemic right ventricle. Congenit Heart Dis. 2011;6(2):147-56.

9. Walker F. Pregnancy and the various forms of the Fontan circulation.

10. Westbrook RH, Dusheiko G, Williamson C. Pregnancy and liver disease. J Hepatol. 2016;64(4):933-45.

11. Drenthen W, Boersma E, Balci A, Moons P, Roos-Hesselink JW, Mulder BJ, Vliegen HW, van Dijk AP, Voors AA, Yap SC, van Veldhuisen DJ. Predictors of pregnancy complications in women with congenital heart disease. Eur Heart J. 2010;31(17):2124-32.

12. Siu SC, Sermer M, Colman JM, Alvarez AN, Mercier LA, Morton BC, Kells CM, Bergin ML, Kiess MC, Marcotte F, Taylor DA. Prospective multicenter study of pregnancy outcomes in women with heart disease. Circulation. 2001;104(5): 515-21.

13. Cauldwell M, Steer PJ, Swan L, Patel RR, Gatzoulis MA, Uebing A, Johnson MR. Pre-pregnancy counseling for women with heart disease: a prospective study. Int J Cardiol. 2017;240:374-8.

14. Regitz-Zagrosek V, Roos-Hesselink JW, Bauersachs J, Blomström-Lundqvist C, Cifkova R, De Bonis M, lung B, Johnson MR, Kintscher U, Kranke P, Lang IM. 2018 ESC guidelines for the management of cardiovascular diseases during pregnancy: the task force for the management of cardiovascular diseases during pregnancy of the European Society of Cardiology (ESC). Eur Heart J. 2018;39(34):3165-241.

15. Garcia Ropero A, Baskar S, Roos Hesselink JW, Girnius A, Zentner D, Swan L, Ladouceur M, Brown N, Veldtman GR. Pregnancy in women with a Fontan circulation: a systematic review of the literature. Circulation. 2018 May;11(5): e004575.

16. Rosenthal DN, Friedman AH, Kleinman CS, Kopf GS, Rosenfeld LE, Hellenbrand WE. Thromboembolic complications after Fontan operations. Circulation. 1995;92(9):287-93.

17. Alsaied T, Possner M, Lubert AM, Trout AT, Gandhi JP, Garr B, Palumbo JS, Palermo JJ, Lorts A, Veldtman GR, Goldstein SL. Thromboembolic events are independently associated with liver stiffness in patients with Fontan circulation. J Clin Med. 2020;9(2):418.

18. Canobbio MM, Cetta F, Silversides C, Warnes C, Aboulhosn J, Colman J. Pregnancy after Fontan operation: early and late outcomes. J Am Coll Cardiol. 2013;61(10 Supplement):E427.

19. Gouton M, Nizard J, Patel M, Sassolas F, Jimenez M, Radojevic J, Mathiron A, Amedro P, Barre E, Labombarda F, Vaksmann G. Maternal and fetal outcomes of pregnancy with Fontan circulation: a multicentric observational study. Int J Cardiol. 2015;187:84-9.

20. Jahangiri M, Shore D, Kakkar V, Lincoln C, Shinebourne E. Coagulation factor abnormalities after the Fontan procedure and its modifications. J Thorac Cardiovasc Surg. 1997;113(6):989-93.

21. Triedman JK, Newburger JW. Trends in congenital heart disease: the next decade. Circulation. 2016;133(25):2716-33.

22. Bonner SJ, Asghar O, Roberts A, Vause S, Clarke B, Keavney B. Corrigendum to "cardiovascular, obstetric and neonatal outcomes in women with a previous Fontan repair" [Eur. J. Obstet. Gynaecol. Reprod. Biol. 219 (2017) 53-56]. European journal of obstetrics and gynecology and. Reprod Biol. 2018;221:209.

23. Chugh R. Management of pregnancy in women with repaired CHD or after the Fontan procedure. Curr Treat Options Cardiovasc Med. 2013;15(5):646-62.

24. Arif S, Chaudhary A, Clift PF, Morris RK, Selman TJ, Bowater SE, Hudsmith LE, Thompson PJ, Thorne SA. Pregnancy outcomes in patients with a fontan circulation and proposal for a risk-scoring system: single Centre experience. J Congenital Cardiol. 2017;1(1):10.

25. La Gerche A, Gewillig M. What limits cardiac performance during exercise in normal subjects and in healthy Fontan patients? Int J Pediatr. 2010;2010:1.

26. Regitz-Zagrosek V, Roos-Hesselink JW, Bauersachs J, Blomstrom-Lundqvist C, Cifkova R, De Bonis M, lung B, Johnson MR, Kintscher U, Kranke P, Lang IM. 
2018 ESC guidelines for the management of cardiovascular diseases during pregnancy. Kardiologia Polska (Polish Heart Journal). 2019;77(3):245-326.

27. Thorne S, MacGregor A, Nelson-Piercy C. Risks of contraception and pregnancy in heart disease. Heart. 2006;92(10):1520-5.

28. Cauldwell M, Gatzoulis M, Steer P. Congenital heart disease and pregnancy: a contemporary approach to counselling, pre-pregnancy investigations and the impact of pregnancy on heart function. Obstet Med. 2017;10(2):53-7.

29. Presbitero P, Somerville J, Stone S, Aruta E, Spiegelhalter D, Rabajoli F. Pregnancy in cyanotic congenital heart disease. Outcome of mother and fetus. Circulation. 1994;89(6):2673-6.

30. Ordonez MV, Trinder J, Curtis SL. Success in a Fontan pregnancy: how important is ventricular function? Cardiol Young. 2019;29(2):225-7.

31. Phillips AL, Cetta F, Kerr SE, Cheek EH, Rose CH, Bonnichsen CR, Phillips SD The placenta: a site of end-organ damage after Fontan operation. A case series. Int J Cardiol. 2019;289:52-5.

32. D'Souza R, Sermer M, Silversides CK. Pregnancy in women with congenital heart disease. Obstet Med. 2015;8(1):18-25.

33. Zentner D, Kotevski A, King I, Grigg L, d'Udekem Y. Fertility and pregnancy in the Fontan population. Int J Cardiol. 2016;208:97-101.

34. Gewillig MH, Lundström UR, Bull C, Wyse RK, Deanfield JE. Exercise responses in patients with congenital heart disease after Fontan repair: patterns and determinants of performance. J Am Coll Cardiol. 1990;15(6): 1424-32.

35. De Leval MR, Dubini G, Jalali H, Pietrabissa R. Use of computational fluid dynamics in the design of surgical procedures: application to the study of competitive flows in cavopulmonary connections. J Thorac Cardiovasc Surg. 1996;111(3):502-13.

36. Kamphuis VP, Elbaz MS, Van Den Boogaard PJ, Kroft LJ, Van Der Geest RJ, De Roos A, Helbing WA, Blom NA, Westenberg JJ, Roest AA. Disproportionate intraventricular viscous energy loss in Fontan patients: analysis by 4D flow MRI. Eur Heart J-Cardiovasc Imaging. 2019;20(3):323-33.

37. McLennan D, Schäfer M, Mitchell MB, Morgan GJ, Ivy D, Barker AJ, Jacobsen R. Usefulness of 4D-flow MRI in mapping flow distribution through failing Fontan circulation prior to cardiac intervention. Pediatr Cardiol. 2019;40(5): 1093-6.

38. Corsini C, Biglino G, Schievano S, Hsia TY, Migliavacca F, Pennati G, Taylor AM, Group MC. The effect of modified Blalock-Taussig shunt size and coarctation severity on coronary perfusion after the Norwood operation Ann Thorac Surg. 2014;98(2):648-54.

39. Bove EL, Migliavacca F, de Leval MR, Balossino R, Pennati G, Lloyd TR, Khambadkone S, Hsia TY, Dubini G. Use of mathematic modeling to compare and predict hemodynamic effects of the modified Blalock-Taussig and right ventricle-pulmonary artery shunts for hypoplastic left heart syndrome. J Thorac Cardiovasc Surg. 2008;136(2):312-20.

40. Tang E, Restrepo M, Haggerty CM, Mirabella L, Bethel J, Whitehead KK, Fogel MA, Yoganathan AP. Geometric characterization of patient-specific total cavopulmonary connections and its relationship to hemodynamics. JACC Cardiovasc Imaging. 2014;7(3):215-24.

41. Esmaily-Moghadam M, Hsia TY, Marsden AL. Modeling of congenital hearts Alliance (MOCHA) investigators. The assisted bidirectional Glenn: a novel surgical approach for first-stage single-ventricle heart palliation. J Thorac Cardiovasc Surg. 2015;149(3):699-705.

42. Corno AF, Owen MJ, Cangiani A, Hall EJ, Rona A. Physiological Fontan procedure. Front Pediatr. 2019;7:196.

43. Desai K, Haggerty CM, Kanter KR, Rossignac J, Spray TL, Fogel MA Yoganathan AP. Haemodynamic comparison of a novel flow-divider Optiflo geometry and a traditional total cavopulmonary connection. Interact Cardiovasc Thorac Surg. 2013;17(1):1-7.

44. Kung E, Perry JC, Davis C, Migliavacca F, Pennati G, Giardini A, Hsia TY, Marsden A. Computational modeling of pathophysiologic responses to exercise in Fontan patients. Ann Biomed Eng. 2015;43(6):1335-47.

45. Carson J, Lewis M, Rassi D, Van Loon R. A data-driven model to study uteroovarian blood flow physiology during pregnancy. Biomech Model Mechanobiol. 2019;18(4):1155-76.

46. Corsini C, Cervi E, Migliavacca F, Schievano S, Hsia TY, Pennati G. Mathematical modelling of the maternal cardiovascular system in the three stages of pregnancy. Med Eng Phys. 2017;47:55-63.

47. Schäfer M, Frank BS, Humphries SM, Hunter KS, Carmody KL, Jacobsen R, Mitchell MB, Jaggers J, Stone ML, Morgan GJ, Barker AJ. Flow profile characteristics in Fontan circulation are associated with the single ventricle dilation and function: principal component analysis study. Am J Phys Heart Circ Phys. 2020;318(5):H1032-40.

48. Ruijsink B, Zugaj K, Wong J, Pushparajah K, Hussain T, Moireau P, Razavi R, Chapelle D, Chabiniok R. Dobutamine stress testing in patients with Fontan circulation augmented by biomechanical modeling. PLoS One. 2020 Feb 21; 15(2):e0229015.

49. Wilson BJ, Watson MS, Prescott GJ, Sunderland S, Campbell DM, Hannaford $P$, Smith WC. Hypertensive diseases of pregnancy and risk of hypertension and stroke in later life: results from cohort study. Bmj. 2003:326(7394):845.

\section{Publisher's Note}

Springer Nature remains neutral with regard to jurisdictional claims in published maps and institutional affiliations.

\section{Ready to submit your research? Choose BMC and benefit from:}

- fast, convenient online submission

- thorough peer review by experienced researchers in your field

- rapid publication on acceptance

- support for research data, including large and complex data types

- gold Open Access which fosters wider collaboration and increased citations

- maximum visibility for your research: over $100 \mathrm{M}$ website views per year

At BMC, research is always in progress.

Learn more biomedcentral.com/submissions 